\title{
SCIDOC

\section{Voice Therapy outcomes in Type-I Sulcus Vocalis: Case Studies}

\author{
Research Article
}

Kumar $\mathrm{R}^{1 *}$, Sharma $\mathrm{P}^{2}$, Vir $\mathrm{D}^{3}$, Panda $\mathrm{NK}^{4}$

${ }^{1}$ Junior Speech Therapist, Speech and Hearing Unit, Department of Otolayngology, PGIMER, Chandigarh, India.

${ }^{2}$ BASLP Student, Speech and Hearing Unit, Department of Otolayngology, PGIMER, Chandigarh, India.

${ }^{3}$ Tutor, Speech and Hearing Unit, Department of Otolayngology, PGIMER, Chandigarh, India.

${ }^{4}$ Professor \& Head, Department of Otolaryngology, PGIMER, Chandigarh, India.

\section{Abstract}

In Sulcus vocalis, a groove on the medial surface of the free edge of varying etiologies in which the mucosal waves are diminished or absent during phonation affects the vocal efficiency. Two cases of physiological based etiology of type-I sulcus vocalis (according to Ford's classification) taken in consideration for voice therapy using vocal hygiene, vocal function exercises and resonant voice therapy. Both cases showed improvement on overall techniques used to improve the vocal efficiency and the timbre of the voice. So, before going for surgical management the type of sulcus vocalis differentiation and the safe and adjuvant voice therapy should be recommended.

Keywords: Sulcus Vocalis; Voice.

\section{Introduction}

Sulcus vocalis is characterized as scar type lesion or longitudinal fissure/groove on the medial surface of free edge of the vocal folds [1]. Luchsinger \& Arnold assumed that the sulcus vocalis to be caused by migration of the vocal fold epithelium in to the normally convex lamina propria, causing a cleft in the vocal fold which alters the way of vocal folds osscilation causing voice changes. Etiologies of sulcus vocalis are not completely clarified. Although some authors suspect it is due to laryngeal infections, degeneration of benign lesions, chronic vocal abuse, micro vascular lesions or secondary to surgery or vocal trauma. It also can be congenital which is due to defect in development of the 4th and 6th brachial arches [2]. Ford proposed a classification for sulcus vocalis as Type-I (superficial type), Type-IIa (deep type) and Type-IIb (pouch type) based on the extent of tissues involved [3]. Varieties of micro surgical techniques such as resection, reconstruction etc. are employed to cure [4-6]. The sulcus vocalis is challenging voice disorder both in diagnosing and treating. In most of the clinic, differentiation for type of sulcus vocalis and voice therapy is not much preferred which can be helpful in helpful and effective treatment tool.

\section{Case Studies}

Two adult cases diagnosed as type-I sulcus vocalis of physiological origin according to Ford's classification by an otolaryngologist through stroboscopic examination were studied. Both cases reported with complaints of hoarse and weak voice with reduced variation of vocal pitch and loudness without family history of such a voice related disorder. Symptomatically patients were primarily treated for gastric reflux disorder followed by vocal hygiene program and resonant voice therapy techniques to improve the vocal efficiency and timbre of the voice. Both cases received resonant voice therapy and vocal function exercise, 1 session per week for 8 weeks. GRBAS scale and Dr. Speech instruments were used to evaluate voice perceptually and objectively respectively before and after treatment in both cases.

\section{Case 1}

41 years female reported with chief complaints of change in voice since 2-3 years with soon fatigues of voice and inability to maintain sufficient variation of pitch and loudness during conversation. Patient was a non-professional voice user with vocal abusive behavior and had chronic laryngopharyngeal reflux (LPR)

\author{
*Corresponding Author: \\ Rawish Kumar, MASLP, \\ Junior Speech Therapist, Speech \& Hearing Unit, Department of Otolaryngology, Postgraduate Institute of Medical Education and Research, Chandigarh, India \\ E-mail: rawishkumar@gmail.com \\ Received: September 08, 2016 \\ Accepted: October 10, 2016 \\ Published: October 13, 2016 \\ Citation: Kumar R, Sharma P, Vir D, Panda NK (2016) Voice Therapy Outcomes in Type-I Sulcus Vocalis: Case Studies. Int J Clin Exp Otolaryngol. 2(5), 48-50. \\ doi: http://dx.doi.org/10.19070/2572-732X-160009
}

Copyright: Kumar $\mathbf{R}^{\circ}$ 2016. This is an open-access article distributed under the terms of the Creative Commons Attribution License, which permits unrestricted use, distribution and reproduction in any medium, provided the original author and source are credited. 
Table 1. Comparisons of GRBAS Scale Pre and Post Voice Therapy.

\begin{tabular}{|c|c|c|c|c|}
\hline \multirow{2}{*}{ Parameter } & \multicolumn{2}{|c|}{ Case 1 } & \multicolumn{2}{c|}{ Case 2 } \\
\cline { 2 - 5 } & Pre & Post & Pre & Post \\
\hline Grade & 3 & 1 & 3 & 1 \\
\hline Roughness & 2 & 0 & 3 & 1 \\
\hline Breathiness & 3 & 0 & 3 & 0 \\
\hline Asthenia & 1 & 0 & 2 & 0 \\
\hline Strain & 1 & 0 & 1 & 0 \\
\hline MPD & 6 & 12 & 7 & 15 \\
\hline
\end{tabular}

Table 2: Comparisons of Pre and Post Voice Therapy Objectively.

\begin{tabular}{|c|c|c|c|c|}
\hline \multirow{2}{*}{ Parameter } & \multicolumn{2}{|c|}{ Case 1 } & \multicolumn{2}{c|}{ Case 2 } \\
\cline { 2 - 5 } & Pre & Post & Pre & Post \\
\hline Habitual Fo $(\mathrm{Hz})$ & 232 & 205 & 149 & 135 \\
\hline Jitter $(\%)$ & 3.31 & 0.67 & 4.02 & 0.84 \\
\hline Shimmer $(\%)$ & 3.97 & 1.01 & 6.76 & 1.94 \\
\hline Fo Tremor $(\mathrm{Hz})$ & 3.41 & 1.69 & 4.80 & 1.70 \\
\hline Mean Fo $(\mathrm{Hz})$ & 231.51 & 209.51 & 143.15 & 138.51 \\
\hline Max Fo $(\mathrm{Hz})$ & 239 & 209 & 151 & 141 \\
\hline Min Fo $(\mathrm{Hz})$ & 228 & 201 & 139 & 132 \\
\hline NNE $(\mathrm{dB})$ & -3.54 & -9.55 & -1.55 & -10.15 \\
\hline HNR $(\mathrm{dB})$ & 8.69 & 15.74 & 9.69 & 12.58 \\
\hline
\end{tabular}

disorder. GRBAS scale and objective assessment before and after voice therapy are shown in Table 1 and Table 2 respectively. Comparison revealed reduction in severity of dysphonia and improvement in overall vocal efficiency after therapy. The phonation duration (MPD) also improved from 6 seconds to approximately 11 seconds.

\section{Case 2}

38 years old male who had dysphonia since approximately 3 years with chief complaints of change in voice, unable to converse for longer time and decreased loudness and LPR as associated problem. Subject was a professional voice user. Subject was a primary school teacher with vocal abusive behavior. There was an improvement in overall voice quality observed after voice therapy. The MPD after voice therapy improved from 7 seconds to 15 seconds. The perceptual and objective assessment prior to voice therapy and post voice therapy are shown in Table 1 and Table 2 respectively of case 2 .

\section{Discussion}

Voice therapy techniques are useful and safe adjuvant treatment rather than surgery. Pathophysiological voice changes in sulcus vocalis produce a glottal gap and diminished or absent mucosal wave during phonation. This decreased pliability restricts the Bernoulli and myoelastic effects, whereby transglottic airflow medializes the leading edge of the vocal fold and it result in a higher fundamental frequency with significantly reduced harmonics and harsh voice quality. The maintenance of vocal hygiene program and treatment for LPR helped in removal of vocal hyper-function and abusive behaviors as well as vocal changes due to LPR [7].
Vocal function exercises and Lessac-Madsen Resonant Voice Therapy (LMRVT) techniques were introduced after to reduce and establish the laryngeal muscle effort for phonation and normal vocal function respectively. The resonant voice therapy and vocal function exercises appears to produce the clearest and most prominent voice with little effort and decreased risk of injury $[8,9]$. However vocal function exercises strengthen and balance the laryngeal musculature and create a balance among airflow, the laryngeal muscular effort and the tone placement [10].

\section{Conclusion}

Prior to consider surgical treatment approaches the differentiation of type of sulcus vocalis and voice therapy should be recommended.

\section{References}

[1]. Tsuji DH, Sennes LI, Chung D. Minimum structural changes Vocal Folds. In: CAH Campos, Costa HOO. Treaty of Otolaryngology. 1a . ed. Volume IV . Sao Paulo: Roca; 2002, pp. 430-9.

[2]. Witzig E, Cornut G, Bouchayer M, Roch JB, Loire R (1983) Study clinicopathological and treatment of epidermoid cyst and the sulcus of the vocal cord : about 157 cases. The ENT Cahiers. XVIII. N 9: 765-778.

[3]. Ford CN, Inagi K, Khidr A, Bless DM, Gilchrist KW (1996) Sulcus vocalis: a rational analytical approach to diagnosis and management. Ann Otol Rhinol Laryngol. 105: 189-200.

[4]. Remacle M1, Lawson G, Degols JC, Evrard I, Jamart J (2000) Microsurgery of sulcus vergeture with carbon dioxide laser and injectable collagen. Ann Otol Rhinol Laryngol. 109 (2): 141-8.

[5]. Hsiung MW, Kang BH, Pai L, Su WF, Lin YH (2004) Combination of fascia transplantation and fat injection into the vocal fold for sulcus vocalis: long term results. Ann Oto Rhinol Laryngol. 113(5): 359-66.

[6]. Su CY, Tsai SS, Chiu JF, Cheng CA (2004) Medialization laryngoplasty with strap muscle transposition for vocal fold atrophy with or without sulcus vo- 
calis. Laryngoscope. 114(6): 1106-12.

[7]. Meckenzie M (1886) The hygiene of vocal organs. 2nd Edn. Macmillan, London.

[8]. Verdolini K (2000) Case Study: Resonant Voice Therapy. In J. Stemple, Voice therapy: Clinical Studies (2nd ed., pp.46-62). San Diego: Singular Publishing Group, Inc.
[9]. Lessac A (1997) The use and training of the human voice : a bio-dynamic approach to vocal life. $3^{\text {rd }}$ Edn. Mountain View. CA: Mayfield Publising Company, USA.

[10]. Stemple, Joseph (2001) Voice Therapy: Clinical Studies. $2^{\text {nd }}$ Edn. Singular. 41-46. 